The Supporting Information for

Benchmark Theoretical and Experimental Study on ${ }^{15} \mathrm{~N}$ NMR Shifts of Oxidatively Damaged Guanine

Martin Dračínský ${ }^{1}$, Michal Š́ala ${ }^{1}$, Blanka Klepetářová ${ }^{1}$, Jakub Šebera ${ }^{1,2}$, Jiří Fukal ${ }^{1}$, Veronika Holečková $^{1}$, Yoshiyuki Tanaka ${ }^{3}, \operatorname{Radim}$ Nencka $^{1}$, Vladimír Sychrovský $^{1 *}$

${ }^{1}$ Institute of Organic Chemistry and Biochemistry AS CR, v.v.i., Flemingovo náměstí 2, 16610 Praha, Czech Republic

${ }^{2}$ Institute of Physics, Academy of Sciences of the Czech Republic, v.v.i, Na Slovance 2, CZ-

18221 Prague 8, Czech Republic

3 Faculty of Pharmaceutical Sciences, Tokushima Bunri University, 180 Nishihama-Boji, Yamashirocho, Tokushima, Tokushima 980-8578, Japan

*To whom correspondence should be addressed:

Dr. Vladimír Sychrovský

Institute of Organic Chemistry and Biochemistry AS CR

Flemingovo náměstí 2, 16610 Praha, Czech Republic

Phone: 00420220183234

Email: vladimir.sychrovsky@uochb.cas.cz

The supporting information includes:

1. Synthesis of 9-ethyl-guanine (detailed description of chemical synthesis).

2. Computational details: effect of atomic basis on N9 NMR shift and descriptions of methods for dynamical averaging of N9 NMR shift and numerical fitting of the Equation 3.

3. Supporting Figures S1-S9.

4. Supporting Tables S1-S4.

5. Complete references $28,49,51$. 


\section{Synthesis of 9-ethyl-guanine}

6-chloro-9-ethyl-9H-purin-2-amine (2)

A mixture of ethylamine hydrochloride (1.63 g, $20 \mathrm{mmol})$, 2-amino-4,6-dichloro-5formamidopyrimidine $(4.13 \mathrm{~g}, 20 \mathrm{mmol})$ and DIPEA $(12.2 \mathrm{~mL}, 70 \mathrm{mmol})$ in ethanol-water $(1: 1$, $90 \mathrm{~mL}$ ) was heated in an Ace pressure tubes ${ }^{\circledR}$ with back seal bushing heated in an aluminium block (Sigma-Aldrich Co.) for $48 \mathrm{~h}$ at $110{ }^{\circ} \mathrm{C}$. After evaporation the residue was chromatographed on a silica gel column (400 g) in ethyl acetate to afford 2 ( $2.89 \mathrm{~g}, 73 \%)$. NMR spectra and other characteristics matched to those previously reported ${ }^{3}$.

2-amino-9-ethyl-1,9-dihydro-6H-purin-6-one (3)

A solution of $2(750 \mathrm{mg}, 3.81 \mathrm{~mol})$ in $\mathrm{CF}_{3} \mathrm{COOH}-\mathrm{H}_{2} \mathrm{O}(3: 1,16 \mathrm{~mL})$ was left standing at room temperature for 3 days. The solution was concentrated, the residue was co-evaporated with water $(2 \times 5 \mathrm{ml})$, then treated with aq. $\mathrm{NH}_{4} \mathrm{OH}$ and evaporated. The residue was purified by flash chromatography in ethyl acetate-ethanol $(30 \% \rightarrow 80 \%)$ to give $683 \mathrm{mg}(90 \%)$ of guanine derivative 3. Analytical sample was crystalized from water. M.p. $>300{ }^{\circ} \mathrm{C} .{ }^{1} \mathrm{H} \mathrm{NMR}(400 \mathrm{MHz}$, DMSO): $\delta \delta 1.33\left(\mathrm{t}, 3 \mathrm{H}, \mathbf{C H}_{3}-\mathrm{CH}_{2}, \mathrm{~J}_{\mathrm{CH} 3-\mathrm{CH} 2}=7.3\right), 3.95\left(\mathrm{q}, 2 \mathrm{H}, \mathrm{CH}_{3}-\mathbf{C H}_{2}, \mathrm{~J}_{\mathrm{CH} 2-\mathrm{CH} 3}=7.3\right), 6.43$ (bs, 2H, 2-NH $), 7.70$ (s, 1H, H-8), 10.55 (bs, 1H, NH). ${ }^{13} \mathrm{C}$ NMR (101 MHz, DMSO) $\delta 15.4$, 37.7, 116.6, 137.0, 151.0, 153.5, 156.9. ESI MS m/z (\%): 202.1 (100) [M+H]; HRMS ESI $\left(\mathrm{C}_{7} \mathrm{H}_{10} \mathrm{ON}_{5}\right)$ calculated: 180.08799 ; found: 180.08784 .

6-(benzyloxy)-9-ethyl-9H-purin-2-amine (4)

A mixture of compound $2(1 \mathrm{~g}, 5.08 \mathrm{mmol})$, potassium carbonate $(1.06 \mathrm{~g}, 7.6 \mathrm{mmol})$ and DABCO (114 mg, $1.02 \mathrm{mmol})$ in benzylalcohol $(9.5 \mathrm{~mL})$ was heated at $75{ }^{\circ} \mathrm{C}$ for $16 \mathrm{~h}$. Volatiles were evaporated (rotary evaporator, bath $90{ }^{\circ} \mathrm{C}$ ) and residue was chromatographed on silica gel column with ethyl acetate. It was obtained $1.041 \mathrm{~g}(76 \%)$ of the product 4. M.p. $164-165{ }^{\circ} \mathrm{C} .{ }^{1} \mathrm{H}$ NMR (500MHz, DMSO): $\delta 1.33$ (t, 3H, $\mathbf{C H}_{3}-\mathrm{CH}_{2}, \mathrm{~J}_{\mathrm{CH} 3-\mathrm{CH} 2}=7.3$ ), 4.03 (q, 2H, $\mathrm{CH}_{3}-\mathbf{C H}_{2}, \mathrm{~J}_{\mathrm{CH} 2}$ $\left.\mathrm{CH}_{3}=7.3\right), 5.49$ (bs, 2H, O-CH$), 6.45$ (bs, 2H, 2-NH $), 7.34(\mathrm{~m}, 1 \mathrm{H}, \mathrm{p}), 7.39$ (m, 2H, m), 7.49 (m, 2H, o), 7.88 (s, 1H, H-8). ${ }^{13} \mathrm{C}$ NMR (125 MHz, DMSO): $\delta 15.41\left(\mathbf{C H}_{3}-\mathrm{CH}_{2}\right), 37.97\left(\mathrm{CH}_{3^{-}}\right.$ $\left.\mathbf{C H}_{2}\right), 67.00\left(\mathrm{O}-\mathrm{CH}_{2}\right), 114.00$ (C-5), 128.26 (C-p), 128.64 (C-m), 128.69 (C-o), 136.95 (C-i), 139.73 (C-8), 154.43 (C-4), 159.85 (C-2), 160.23 (C-6). ESI MS m/z (\%): 270.3 (100) [M+H], $292.3(80)[\mathrm{M}+\mathrm{Na}]$; HRMS ESI $\left(\mathrm{C}_{14} \mathrm{H}_{16} \mathrm{ON}_{5}\right)$ calculated: 270.13494 ; found: 270.13500.

6-(benzyloxy)-8-bromo-9-ethyl-9H-purin-2-amine (5)

Starting material 4 (906 mg, $3.36 \mathrm{mmol})$ was co-evaporated with DMF (60 mL) and then dissolved in DMF (60 mL). To this mixture was at r.t. added NBS (658 mg, $3.7 \mathrm{mmol}$ ) and reaction mixture was stirred at r.t. for $15 \mathrm{~h}$. Reaction mixture was evaporated and product were isolated by column chromatography (petrolether: ethyl acetate, $40 \% \rightarrow 60 \%$ ). It was obtained 936 mg (80\%) of the product 5. M.p. $146-152{ }^{\circ} \mathrm{C}$ (decomp.). ${ }^{1} \mathrm{H}$ NMR (500MHz, DMSO): $\delta 1.26$ (t, $3 \mathrm{H}, \mathbf{C H}_{3}-\mathrm{CH}_{2}, \mathrm{~J}_{\mathrm{CH} 3-\mathrm{CH} 2}=7.1$ ), 4.03 (q, 2H, $\left.\mathrm{CH}_{3}-\mathbf{C H}_{2}, \mathrm{~J}_{\mathrm{CH} 2-\mathrm{CH} 3}=7.1\right), 5.47$ (bs, 2H, O-CH $\mathbf{C H}_{2}, 6.64$ (bs, 2H, 2-NH $\left.\mathrm{NH}_{2}\right) 7.35(\mathrm{~m}, 1 \mathrm{H}, \mathrm{p}), 7.40(\mathrm{~m}, 2 \mathrm{H}, \mathrm{m}), 7.49(\mathrm{~m}, 2 \mathrm{H}, \mathrm{o}) .{ }^{13} \mathrm{C} \mathrm{NMR}(125 \mathrm{MHz}$, DMSO): $\delta 14.70\left(\mathbf{C H}_{3}-\mathrm{CH}_{2}\right), 38.81\left(\mathrm{CH}_{3}-\mathbf{C H}_{2}\right), 67.23\left(\mathrm{O}-\mathrm{CH}_{2}\right), 114.16(\mathrm{C}-5), 124.36(\mathrm{C}-8)$, 
128.33 (C-p), 128.64 (C-m), 128.70 (C-o), 136.65 (C-i), 155.05 (C-4), 159.05 (C-6), 159.95 (C2). ESI MS $m / z(\%): 370.2 / 372.2(100 / 96)$ [M+Na], 348/350 (60/58) [M+H]; HRMS ESI $\left(\mathrm{C}_{14} \mathrm{H}_{15} \mathrm{ON}_{5} \mathrm{Br}\right)$ calculated: 348.04545 ; found: 348.04559 .

2-amino-9-ethyl-7,9-dihydro-1H-purine-6,8-dione (6)

Bromo derivative $5(850 \mathrm{mg}, 2.44 \mathrm{mmol})$ was dissolved in mixture of dioxane $(12 \mathrm{~mL})$ and conc. hydrochloric acid $\left(28.4 \mathrm{~mL}\right.$ ). Reaction mixture was heated at $95{ }^{\circ} \mathrm{C}$ (oil bath) for $72 \mathrm{~h}$ and evaporated to dryness. Mixture was co-evaporated with ethanol $(3 \times 50 \mathrm{~mL})$, then treated with aq. $\mathrm{NH}_{4} \mathrm{OH}$ and evaporated. Residue was again co-evaporated with ethanol (3 x $50 \mathrm{~mL}$ ). Residual solid was dissolved in ethanol-water $(1: 1)$ and left crystalized in fridge overnight. Solid was filtered off and twice chromatographed on silica gel column (ethylacetate $\rightarrow$ ethyl acetate:ethanol 1:1). We obtained $238 \mathrm{mg}(50 \%)$ of the product 6. Samples were then crystalized from water and water : ethanol : dimethylformanide 6:4:1 with catalytic amount of guanosine. M.p. > $300{ }^{\circ} \mathrm{C} .{ }^{1} \mathrm{H}$ NMR (500MHz, DMSO): $\delta 1.14$ (t, 3H, $\left.\mathrm{CH}_{3}-\mathrm{CH}_{2}, \mathrm{~J}_{\mathrm{CH} 3-\mathrm{CH} 2}=7.1\right), 3.62$ (q, $2 \mathrm{H}, \mathrm{CH}_{3}-\mathrm{CH}_{2}, \mathrm{~J}_{\mathrm{CH} 2-\mathrm{CH} 3}=7.1$ ), 6.47 (bs, 2H, 2-NH2), 10.52 (bs, H1, NH), 10.63 (bs, H1, NH). 13C NMR (125 MHz, DMSO): $\delta 14.21\left(\mathrm{CH}_{3}-\mathrm{CH}_{2}\right), 34.17\left(\mathrm{CH}_{3}-\mathrm{CH}_{2}\right), 98.41,148.07,151.23$, 152.23, 153.77. ESI MS m/z (\%): 218.1 [M+Na]. HRMS ESI $\left(\mathrm{C}_{7} \mathrm{H}_{9} \mathrm{O}_{2} \mathrm{~N}_{5} \mathrm{Na}\right)$ calculated: 218.06485; found: 218.06485 . 


\section{Computational details}

\section{Effect of atomic basis on N9 NMR shift}

The dependence of $\Delta \delta_{\mathrm{N} 9}$ NMR shift on kind of Gaussian atomic basis functions was calculated for the geometries obtained as global energy minima of G and OG molecules (Table 1). The $\Delta \delta_{\mathrm{N} 9}$ NMR shift calculations included the Pople's, Dunning's cc-pVnZ and aug-cc-pVnZ (n=D, T, Q), and Kutzelnigg's Iglo-n $\left(\mathrm{n}=\mathrm{II}\right.$, III) basis sets (Table S1). The calculated $\Delta \delta_{\mathrm{N} 9}$ NMR shifts varied between -28.9 ppm (aug-cc-pVQZ) and -25.7 ppm $(6-31+\mathrm{G}(\mathrm{d}))$. All the $\Delta \delta_{\mathrm{N} 9} \mathrm{NMR}$ shifts decreased for larger atomic bases within each series, except for the Pople's 6-31+G(d) calculation and the IgloII/III calculations (Figure S1). For the cc-pVTZ and larger bases including the Dunning's TZ, QZ and Iglo-III $\Delta \delta_{\mathrm{N} 9}$ NMR shift varied by $0.8 \mathrm{ppm}$. The $\Delta \delta_{\mathrm{N} 9}$ NMR shifts calculated employing Iglo-III, cc$\mathrm{pVnZ}(\mathrm{n}=\mathrm{T}, \mathrm{Q})$ and aug-cc-pVTZ varied only by $0.3 \mathrm{ppm}$. As compared to $\Delta \delta_{\mathrm{N} 9}$ NMR shifts calculated with these medium-size bases, the $\Delta \delta_{\mathrm{N} 9}$ NMR shift calculated with aug-cc-pVQZ basis decreased further by ca $0.5 \mathrm{ppm}$, however, the basis would be hardly applicable for dynamical averaging of MD snapshots. The effects of geometry and solvent geometry on $\Delta \delta_{\mathrm{N} 9}$ NMR shift were calculated with Iglo-III, cc-pVQZ and aug-cc-pVQZ bases for geometries optimized with different bases and different kind of implicit solvent as described in the Table S2. In these calculations the ccpVQZ and aug-cc-pVQZ bases performed quite similarly and the respective $\Delta \delta_{\mathrm{N} 9}$ NMR shifts differed less than $0.2 \mathrm{ppm}$. The $\Delta \delta_{\mathrm{N} 9}$ NMR shifts varied less than $0.4 \mathrm{ppm}$ for differently optimized geometries and different kind of solvent (Figure $\mathrm{S} 2$ ). The $6-311++\mathrm{G}(\mathrm{d}, \mathrm{p})$ basis was used for optimization of geometry and the Iglo-III basis was used for calculation of $\Delta \delta_{\mathrm{N} 9}$ NMR shifts.

\section{Dynamical averaging of N9 NMR shift}

Two methods for obtaining dynamically averaged $\Delta \delta_{\mathrm{N} 9}$ NMR shifts were employed. The adiabatic averaging employed calculated dependence of $\sigma_{\mathrm{N} 9}$ shielding on $\chi$ torsion angle that was dynamically averaged with MD calculated $\chi$-probablity distribution. The $\sigma_{\mathrm{N} 9}(\chi)$ dependence was calculated for adiabatically optimized geometries calculated with the B3LYP method, 6-311++G(d,p) basis and PCM DMSO solvent for geometries optimized with fixed $\chi$ torsion angle so that complete rotation of 9-ethyl group with the step of $10^{\circ}$ was obtained (Table S4). The $\chi$-probability distribution and $\kappa^{\prime}$-probability distribution were calculated with MD as follows. The frequencies $f_{n}, n=1, \ldots, 36$, corresponding to occurrences of $\chi$ and $\kappa^{\prime}$ torsion within 36 intervals with the range of $10^{\circ}$ were summed for $4000 \mathrm{MD}$ snapshots. The $\chi$ - and $\kappa$ '-probability distribution calculated as normalized frequencies $\rho_{n}=f_{n} / 4000, n=1, . ., 36$ described probability of finding $\chi$ and $\kappa$ ' torsion within each of 36 
intervals. The $\sigma_{\mathrm{N} 9}$ shielding was adiabatically averaged as follows: $\sigma_{\mathrm{N} 9}=\Sigma \sigma_{\mathrm{N} 9}\left(\chi_{\mathrm{n}}\right) \cdot \rho_{\mathrm{n}}\left(\chi_{\mathrm{n}}\right), \mathrm{n}=1, \ldots, 36$, where $\chi_{\mathrm{n}}$ was the middle value of within each interval. The MD averaging was calculated as statistical average of $\sigma_{\mathrm{N} 9}$ shieldings calculated for $200 \mathrm{MD}$ snapshot geometries. The MD averaging employed either original or geometry optimized snapshots. The optimized snapshots preserved orientation of 9ethyl group and N9-pyramidalization as was calculated with MD by keeping fixed $\chi$ torsion and the C4-N9-C(H2), C8-N9-C(H2), and C4-N9-C8 valence angles. The MD snapshots were optimized at the B3LYP, 6-311++G(d,p), PCM DMSO level. The MD averaged $\sigma_{\mathrm{N} 9}$ shielding was calculated as arithmetic mean of $\sigma_{\mathrm{N} 9}$ shieldings calculated for 200 snapshots. The standard deviation of the mean $\operatorname{av}_{\mathrm{N} 9}$ was calculated as follows; $\mathrm{s}_{\mathrm{M}}=\left[\left(\Sigma_{\mathrm{k}}\left(\sigma_{\mathrm{N} 9, \mathrm{k}}-\mathrm{av} \sigma_{\mathrm{N} 9}\right)^{2} /(200 \cdot(200-1))\right)\right]^{1 / 2}, \mathrm{k}=1, . ., 200$.

\section{Numerical fitting of the Equation 3}

The a, b, c, d, e, f coefficients in Equation 3 were fitted employing the nonlinear least-squares Marquardt-Levenberg algorithm with the G N U P L O T programme, Version 4.2 for the calculated $\sigma_{\mathrm{N} 9}(\chi)$ dependence (Table S3, Table S4). 


\section{Supporting Figures}

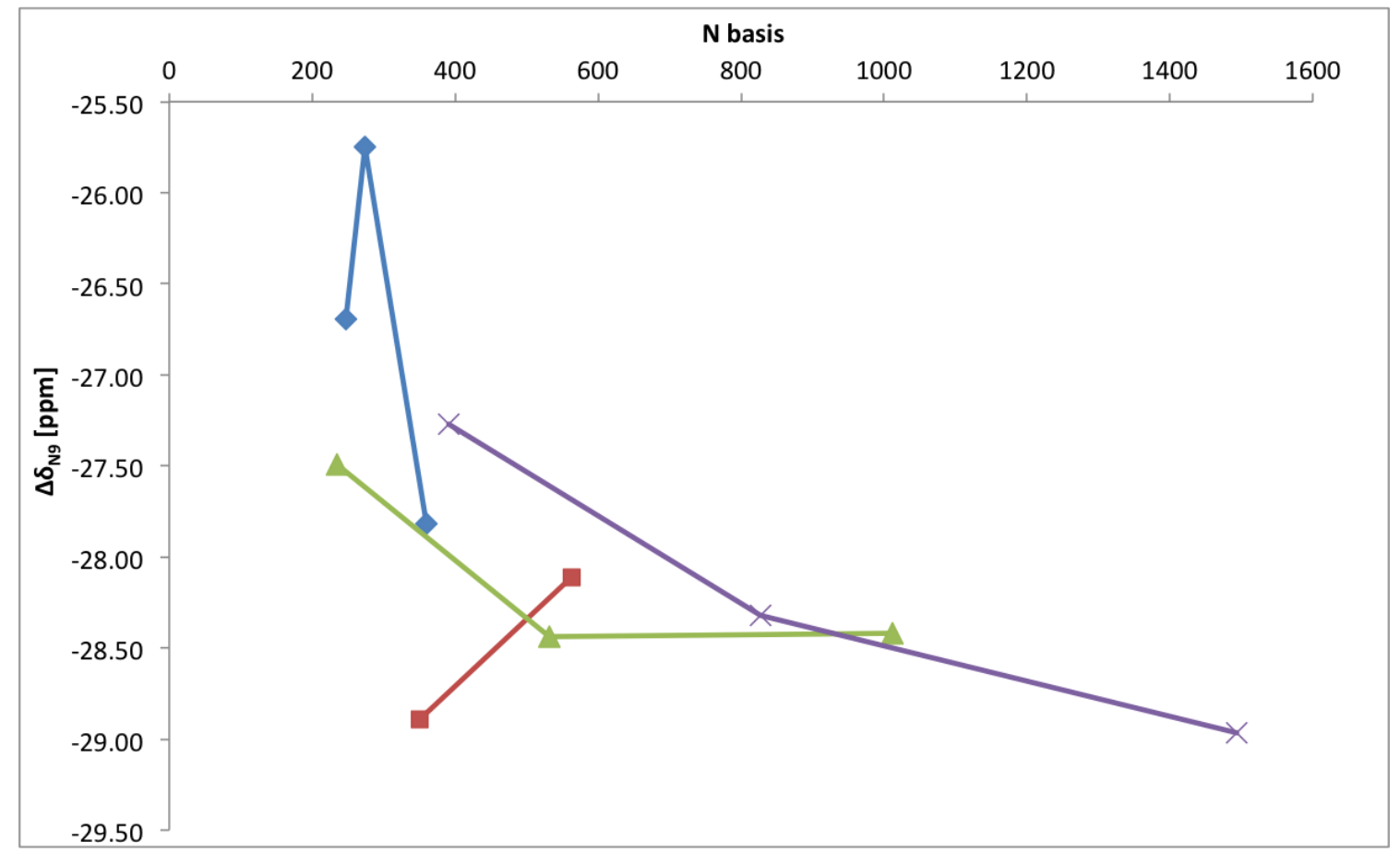

Figure S1. The basis set convergence analysis for $\Delta \delta_{\mathrm{N} 9}$ NMR shift calculated employing the B3LYP method, PCM DMSO implicit solvent, and the Pople's 6-31G(d,p), 6-31+G(d) and 6-311++G(d,p) (blue diamonds), Iglo-II, Iglo-III (red cubes), cc-pVnZ, n = D, T, Q (green triangles), and aug-cc$\mathrm{pVnZ}, \mathrm{n}=\mathrm{D}, \mathrm{T}, \mathrm{Q}$ (violet ex mark) basis sets. $\mathrm{N}$ basis was the averaged number of Gaussian atomic basis functions (Table S1). The geometries of $\mathrm{G}$ and $\mathrm{OG}$ molecules were optimized employing the B3LYP, PCM DMSO, and 6-311++G(d,p) method. 


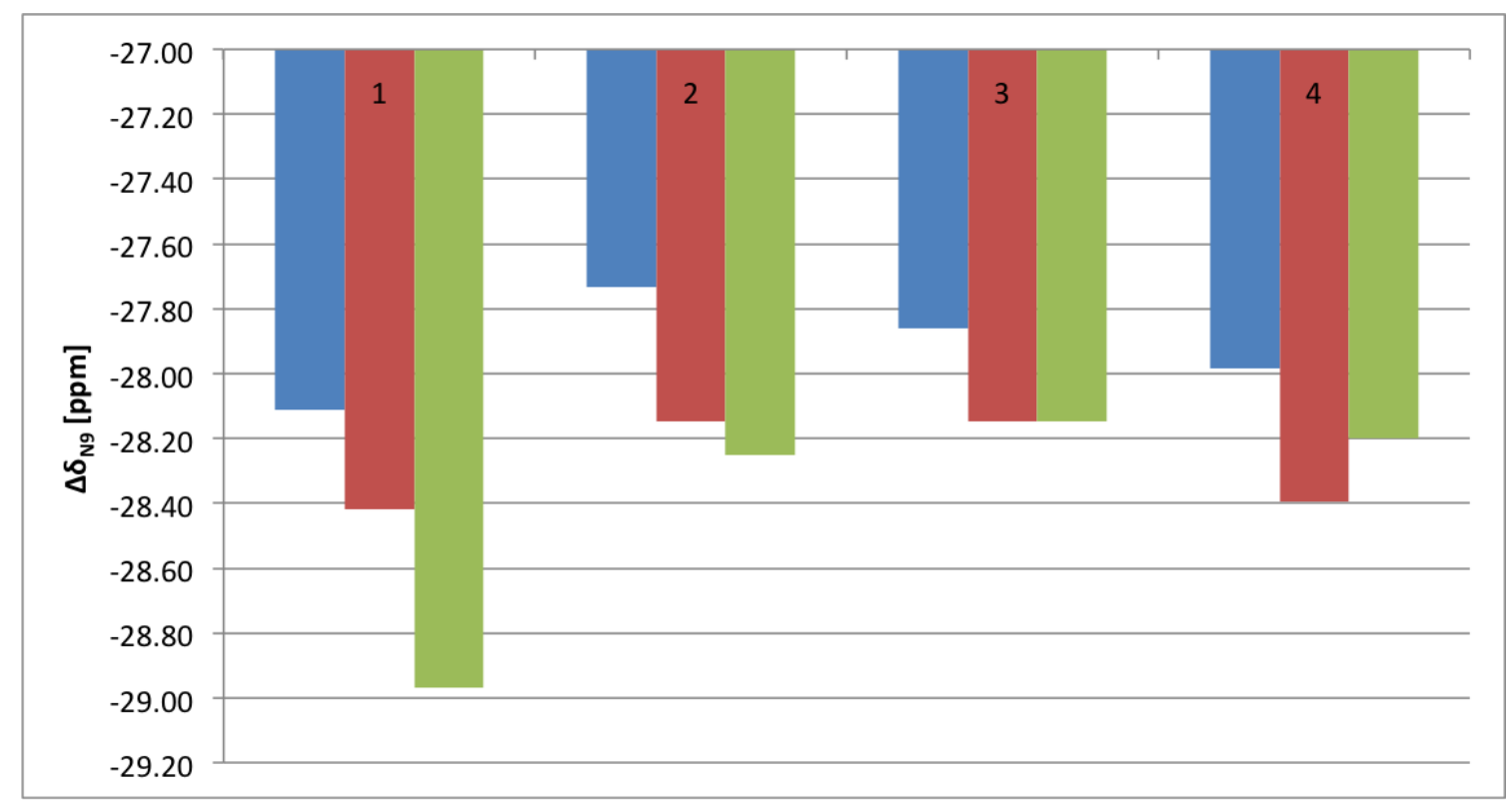

Figure S2. The $\Delta \delta_{\mathrm{N} 9}$ NMR shift calculated employing the B3LYP method, Iglo-III (blue), cc-pVQZ (red) and aug-cc-pVQZ (green) basis, and PCM solvent: 1) DMSO, 2) DMSO, 3) DMSO, and 4) water. The geometries of G and OG molecule were optimized with: 1) B3LYP, PCM DMSO, 6311++G(d,p), 2) B3LYP, PCM DMSO, aug-cc-pVTZ, 3) B3LYP, PCM water, 6-31G(d,p), 4) B3LYP, PCM water, 6-31G(d,p). The values of $\Delta \delta_{\mathrm{N} 9}$ NMR shift can be found in Table S2. 


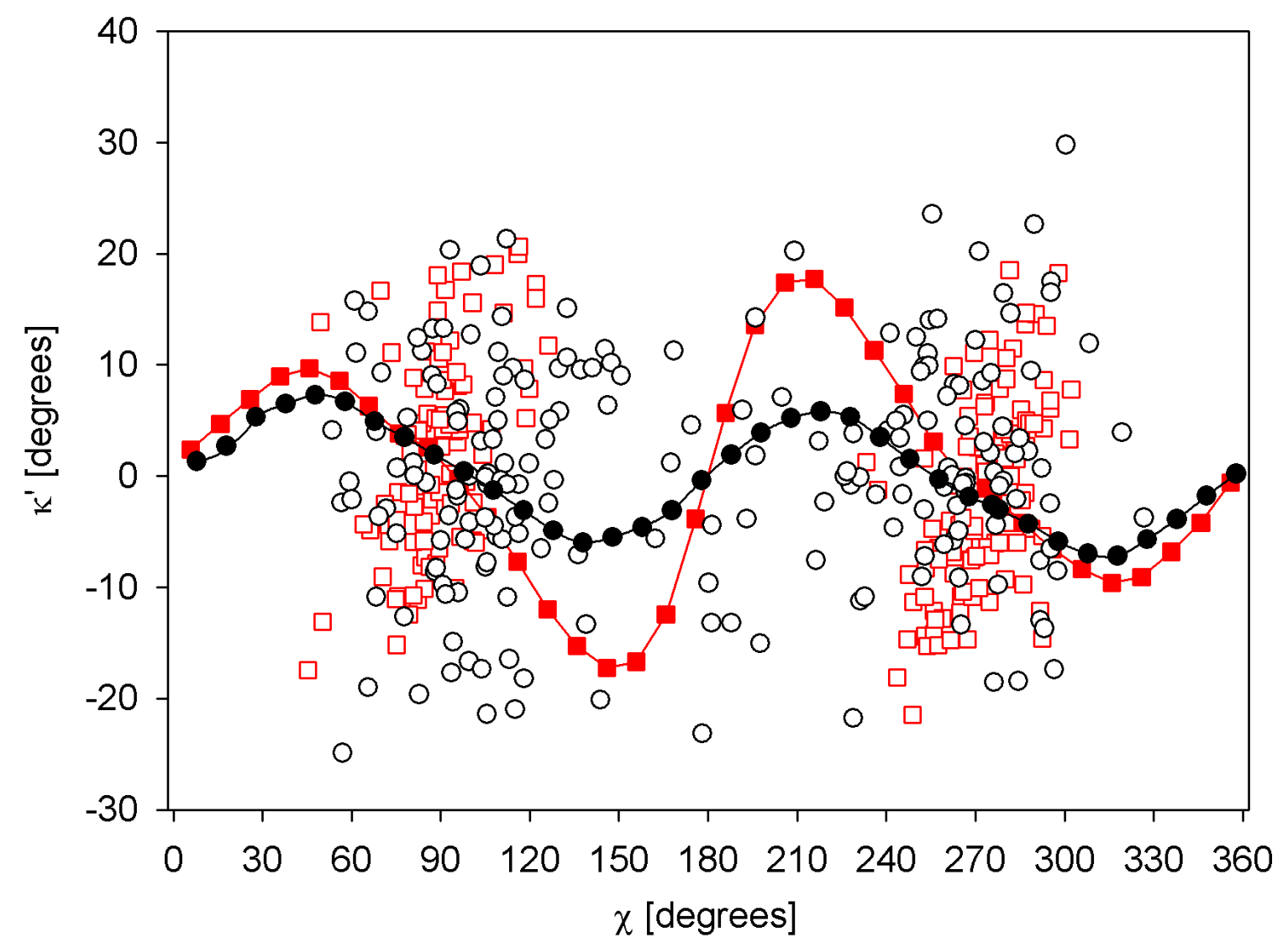

Figure S3. The dependence of adiabatically relaxed $\kappa$ ' torsion on $\chi$ torsion that was fixed in geometry optimization of $\mathrm{G}$ (black filled circle) and OG (red filled square) molecule. The correlation of $\kappa$ ' torsion with $\chi$ torsion calculated for MD snapshot geometries of G (black open circle) and OG (red open square) molecule. The dependence of $\kappa$ ' torsion angle on $\chi$ torsion angle calculated employing the B3LYP method, 6-311++G(d,p) basis and including PCM DMSO solvent. 


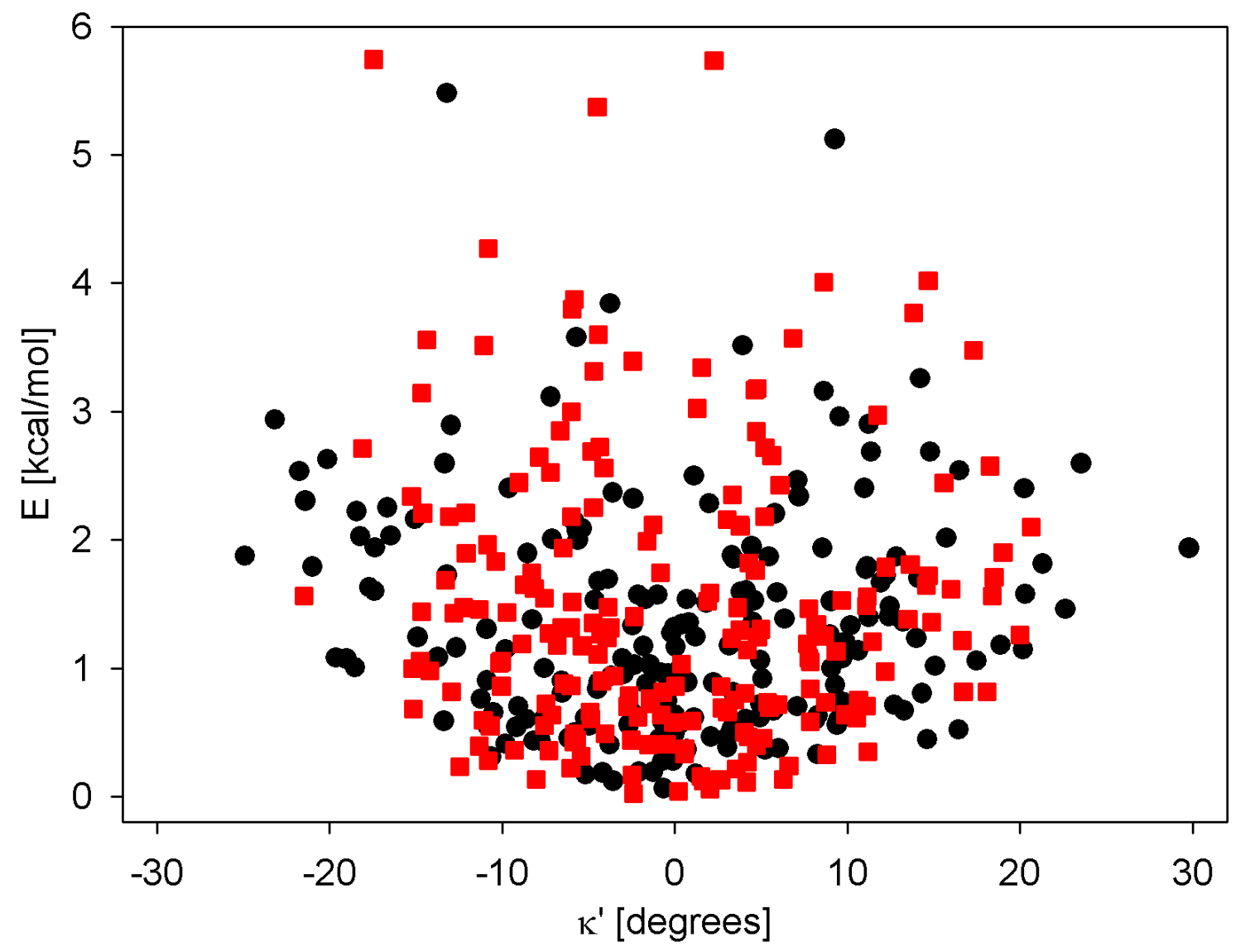

Figure S4. The correlation of relative energies E with $\kappa$ ' torsion calculated employing the B3LYP, 6$311++G(d, p)$, PCM DMSO method for adiabatically relaxed MD snapshots of $G$ (black filled circle) and OG (red filled circle) molecules. 


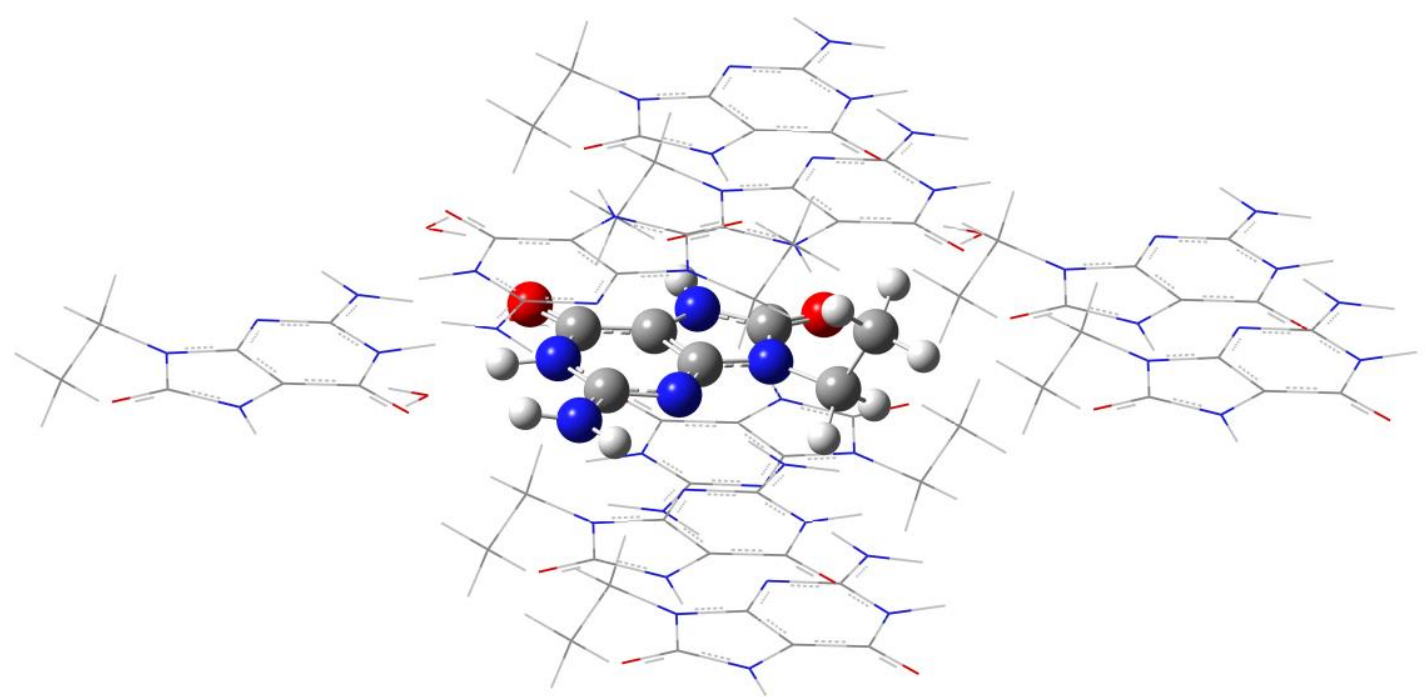

Figure S5. The molecular cluster including OG molecule surrounded by nearest ten OG molecules and four water molecules derived from FURGAA03 crystal structure that was employed in molecular-orbital B3LYP NMR calculations. 


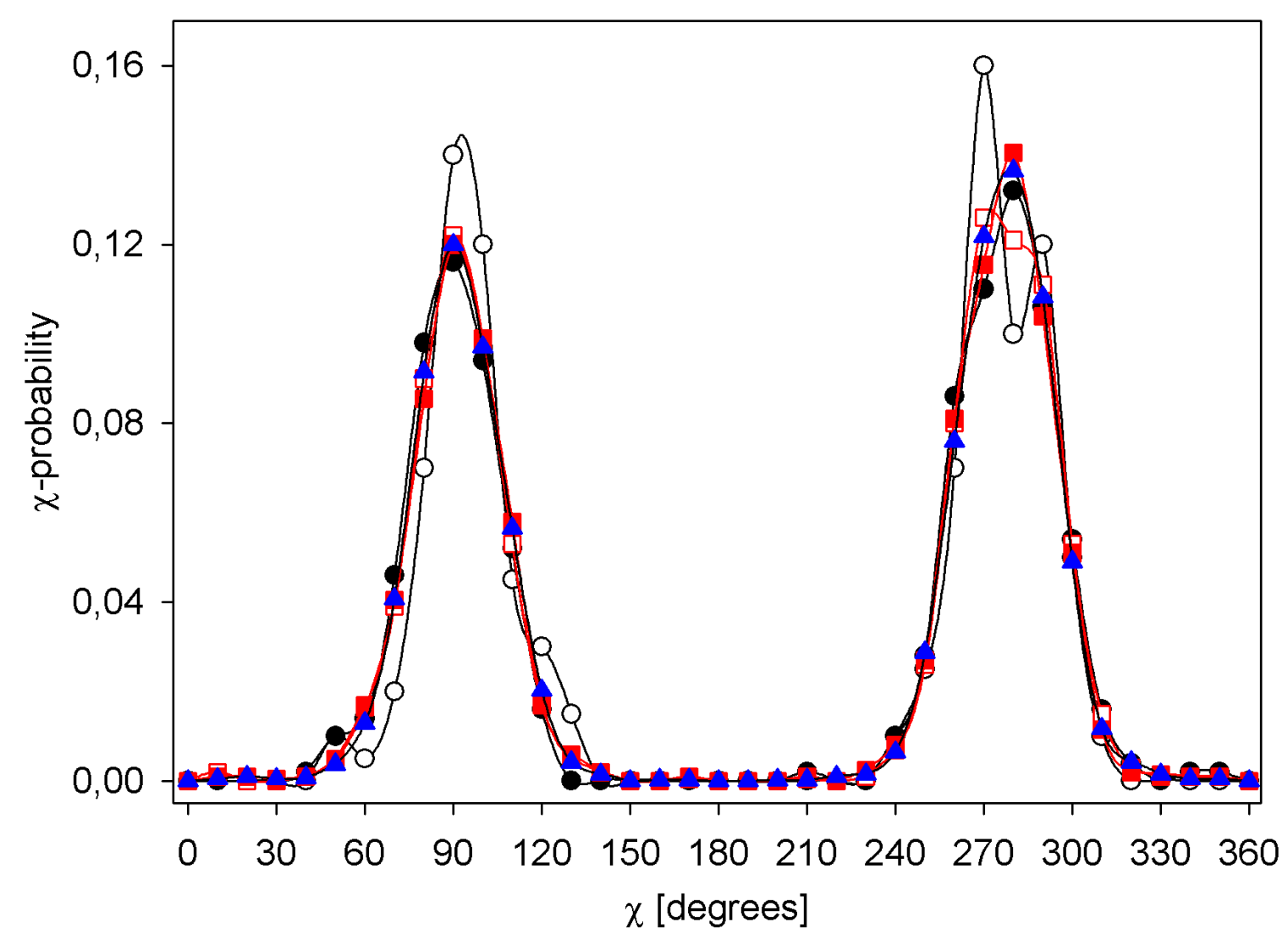

Figure S6. The probability distribution of $\chi$ torsion angle calculated with GAFF MD for OG molecule employing 200 (black open circle), 500 (black filled circle), 1000 (red open square), 2000 (red filled square) and 4000 (blue filled triangle) snap shots. The snapshot of each ensemble were taken from complete ensemble of 4000 snapshots keeping the number of snapshots that separated the selected snapshots constant; i.e. the snapshots of 200-ensable were separated by 20 snapshots in complete 4000 -ensamble, the snapshots 500 -ensable were separated by 8 snapshots, etc. 

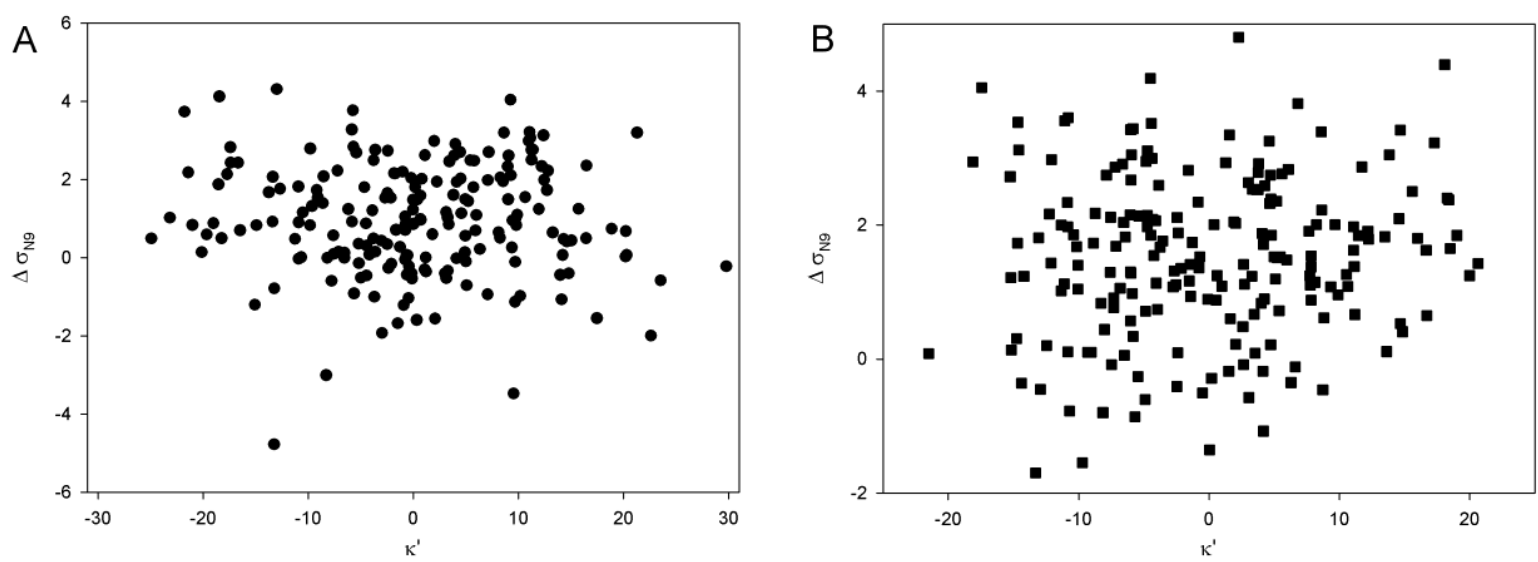

Figure S7. The $\Delta \sigma_{\mathrm{N} 9}$ contribution to NMR shielding owing to N9-pyramidalization calculated for optimized MD snapshots of A) G molecule and B) OG molecule. The $\Delta \sigma_{\mathrm{N} 9}$ in ppm was calculated as $\sigma_{\mathrm{N} 9}$ shielding for snapshot minus the NMR shielding employing the Equation 3 for orientation of 9-ethyl group in MD snapshot. 


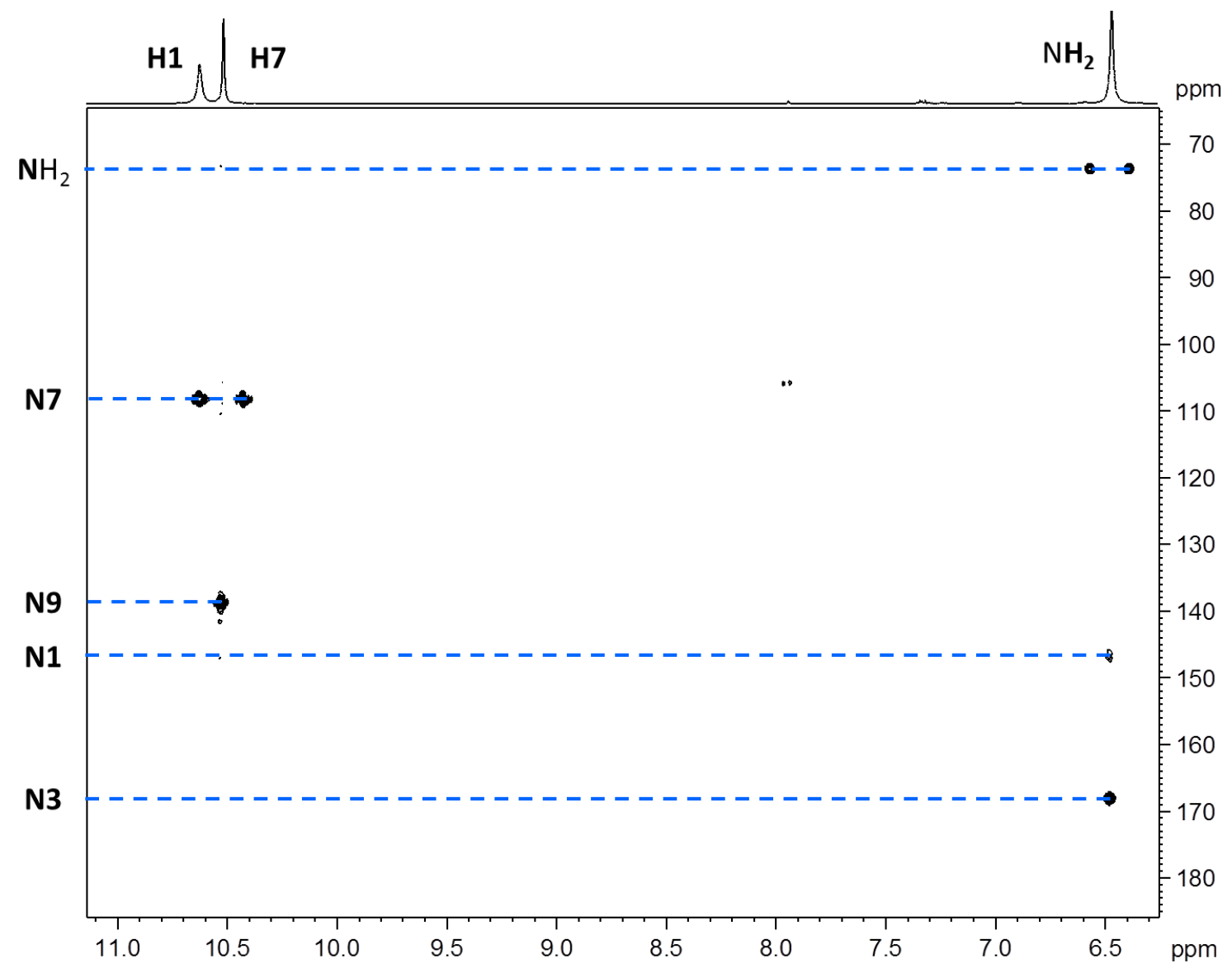

Figure S8. Experimental ${ }^{15} \mathrm{~N}$ liquid-state NMR spectra of OG molecule. The ${ }^{15} \mathrm{~N}$ NMR shifts were referenced to nitromethan $\left(\delta_{\mathrm{R}}=381.7 \mathrm{ppm}\right)$. 


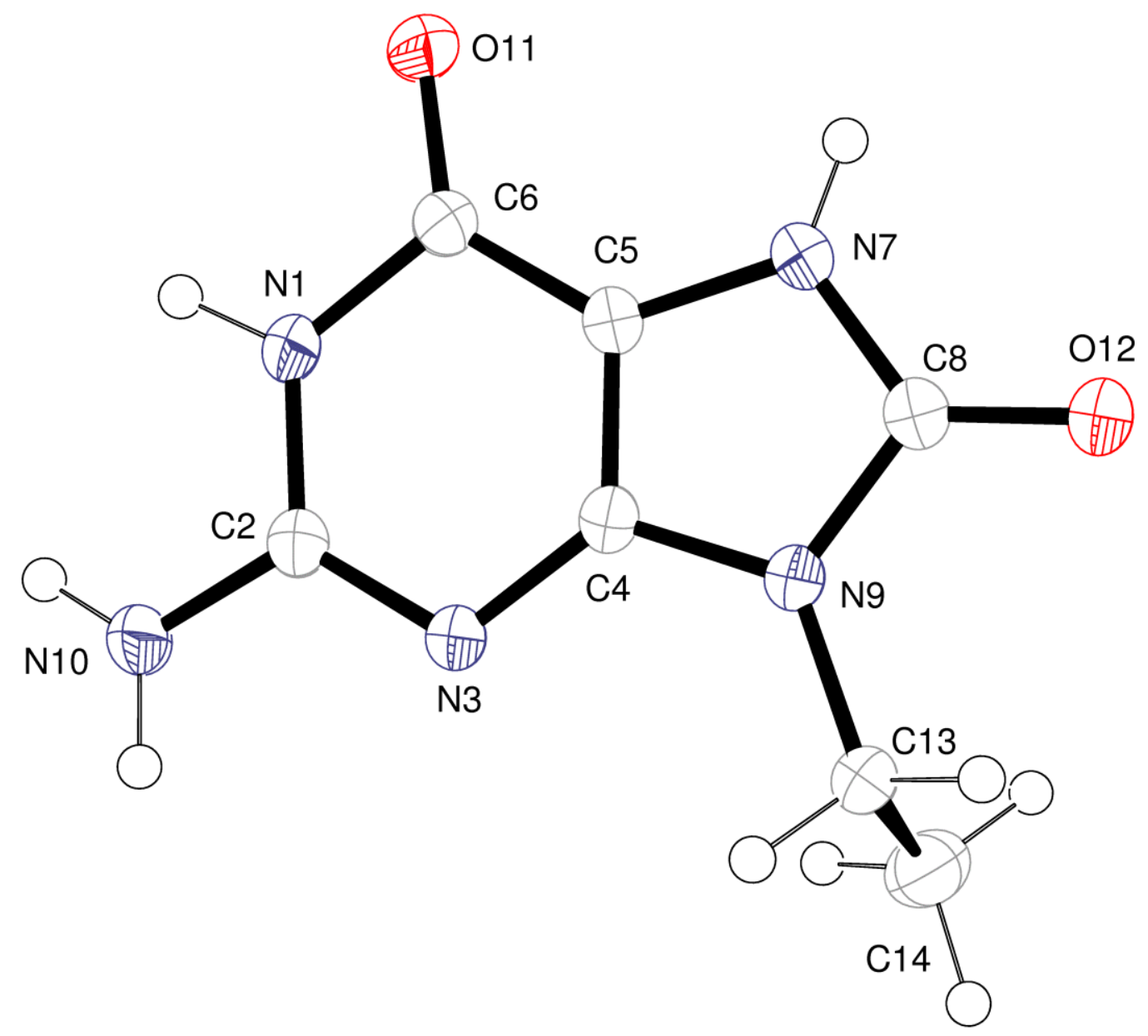

Figure S9. An ORTEP view of OG molecule, displacement ellipsoids shown with $50 \%$ probability. 


\section{SUPPORTING TABLES}

Table $\mathrm{S} 1$. The $\sigma_{\mathrm{N} 9}(\mathrm{G})$ and $\sigma_{\mathrm{N} 9}(\mathrm{OG}) \mathrm{NMR}$ shielding and $\Delta \delta_{\mathrm{N} 9}$ NMR shift in ppm calculated employing different atomic bases.

\begin{tabular}{|ccccccc|}
\hline Basis a) & $\sigma_{\mathrm{N} 9}(\mathrm{OG})$ & $\sigma_{\mathrm{N} 9}(\mathrm{G})$ & $\Delta \delta_{\mathrm{Ng}}{ }^{\mathrm{b})}$ & $\mathrm{N}(\mathrm{OG})$ & $\mathrm{N}(\mathrm{G})$ & $\mathrm{N}$ aver ${ }^{\mathrm{c})}$ \\
6-31G(d,p) & 114.01 & 87.32 & -26.69 & 255 & 240 & 248 \\
6-31+G(d) & 110.95 & 85.20 & -25.74 & 284 & 265 & 275 \\
6-311++G(d,p) & 88.80 & 60.98 & -27.81 & 371 & 349 & 360 \\
Iglo-II & 90.78 & 61.89 & -28.89 & 362 & 340 & 351 \\
Iglo-III & 82.47 & 54.36 & -28.11 & 580 & 545 & 563 \\
cc-pVDZ & 110.36 & 82.87 & -27.49 & 241 & 227 & 234 \\
cc-pVTZ & 91.93 & 63.49 & -28.43 & 546 & 516 & 531 \\
cc-pVQZ & 85.64 & 57.23 & -28.41 & 1040 & 985 & 1013 \\
aug cc-pVDZ & 105.89 & 78.62 & -27.27 & 403 & 380 & 392 \\
aug cc-pVTZ & 90.66 & 62.34 & -28.32 & 851 & 805 & 828 \\
aug cc-pVQZ & 84.80 & 55.84 & -28.96 & 1534 & 1454 & 1494 \\
\hline
\end{tabular}

a) All the basis sets were downloaded from the EMSL Basis Set Exchange web portal https://bse.pnl.gov/bse/portal. Calculations for the global energy minima obtained at the B3LYP, 6-311++G(d,p), PCM DMSO level.

b) $\Delta \delta_{\mathrm{N} 9}=\sigma_{\mathrm{N} 9}(\mathrm{G})-\sigma_{\mathrm{N} 9}(\mathrm{OG})$

c) Averaged number of Gaussian basis functions $N$ aver $=(\mathrm{N}(\mathrm{OG})+\mathrm{N}(\mathrm{G})) / 2$ 
Table S2. The $\Delta \delta_{\mathrm{N} 9}$ NMR shift in ppm calculated employing the largest bases of Iglo and Dunning's series with B3LYP method and different PCM implicit solvent for geometries optimized at different levels.

\begin{tabular}{|c|c|c|c|c|}
\hline & \multicolumn{4}{|c|}{ Method $^{\text {a) }}$} \\
\hline & $6-311++\mathrm{G}(\mathrm{d}, \mathrm{p})$ & Aug-ccpVTZ & $6-31 G(d, p)$ & $6-31 G(d, p)$ \\
\hline & DMSO & DMSO & WATER & WATER \\
\hline Basis $^{\text {b) }}$ & (DMSO) & (DMSO) & (DMSO) & (WATER) \\
\hline Iglo-III & -28.11 & -27.73 & -27.86 & -27.98 \\
\hline cc-pVQZ & -28.41 & -28.14 & -28.14 & -28.39 \\
\hline aug cc-pVQZ & -28.96 & -28.25 & -28.14 & -28.19 \\
\hline
\end{tabular}


Table S3. The coefficients in the Equation 3 describing dependence of $\sigma_{\mathrm{N} 9}$ NMR shielding of G and OG molecules on $\chi$ torsion angle fitted employing nonlinear least-squares MarquardtLevenberg algorithm and the data in Table S4. The rms of residuals was 0.064720 and 0.217717 for $\mathrm{G}$ and $\mathrm{OG}$, respectively.

\begin{tabular}{|c|c|c|}
\hline Coefficient & G & OG \\
\hline $\mathrm{a}$ & 2.04881 & -2.97534 \\
\hline $\mathrm{b}$ & 1.39945 & 3.68046 \\
\hline $\mathrm{c}$ & 0.223131 & 1.73496 \\
\hline $\mathrm{d}$ & 3.49244 & 2.6381 \\
\hline $\mathrm{e}$ & 0.170768 & -0.728945 \\
\hline $\mathrm{f}$ & 54.3541 & 82.6699 \\
\hline
\end{tabular}


Table S4. The $\sigma_{\mathrm{N} 9}(\mathrm{G})$ and $\sigma_{\mathrm{N} 9}(\mathrm{OG})$ shielding in ppm calculated employing the B3LYP, Iglo-III basis, PCM DMSO solvent for geometries optimized with constrained $\chi$ torsion in degrees employing the B3LYP method, 6-311++G(d,p) basis and PCM DMSO implicit solvent. The $\sigma_{\mathrm{N} 9}$ shielding in the last column was calculated employing parameterized Equation 3.

\begin{tabular}{|c|c|c|}
\hline$\chi$ & $\sigma_{\mathrm{N} 9}(\mathrm{G})$ & $\mathrm{Eq} .3 \sigma_{\mathrm{N} 9}(\mathrm{G})$ \\
\hline 7.8 & 61.54 & 61.47 \\
\hline 17.8 & 60.59 & 60.63 \\
\hline 27.8 & 59.17 & 59.36 \\
\hline 37.8 & 57.85 & 57.96 \\
\hline 47.8 & 56.60 & 56.68 \\
\hline 57.8 & 55.62 & 55.67 \\
\hline 67.8 & 54.93 & 54.97 \\
\hline 77.8 & 54.49 & 54.55 \\
\hline 87.8 & 54.34 & 54.37 \\
\hline 97.8 & 54.37 & 54.40 \\
\hline 107.8 & 54.67 & 54.63 \\
\hline 117.8 & 55.07 & 55.03 \\
\hline 127.8 & 55.57 & 55.53 \\
\hline 137.8 & 56.03 & 56.02 \\
\hline 147.8 & 56.32 & 56.40 \\
\hline 157.8 & 56.58 & 56.65 \\
\hline 167.8 & 56.80 & 56.76 \\
\hline 177.8 & 56.87 & 56.80 \\
\hline$\chi$ & $\sigma_{\mathrm{N} 9}(\mathrm{OG})$ & Eq. $3 \sigma_{\mathrm{N} 9}(\mathrm{OG})$ \\
\hline 5.8 & 87.12 & 86.97 \\
\hline 15.8 & 86.59 & 86.66 \\
\hline 25.8 & 85.90 & 86.07 \\
\hline 35.8 & 85.08 & 85.29 \\
\hline 45.8 & 84.42 & 84.41 \\
\hline 55.8 & 83.73 & 83.60 \\
\hline 65.8 & 83.14 & 83.00 \\
\hline 75.8 & 82.71 & 82.69 \\
\hline 85.8 & 82.45 & 82.63 \\
\hline 95.8 & 82.56 & 82.77 \\
\hline 105.8 & 83.01 & 83.05 \\
\hline 115.8 & 83.69 & 83.52 \\
\hline 125.8 & 84.56 & 84.29 \\
\hline 135.8 & 85.57 & 85.45 \\
\hline 145.8 & 86.71 & 86.97 \\
\hline 155.8 & 88.15 & 88.64 \\
\hline 165.8 & 89.96 & 90.08 \\
\hline 175.8 & 91.35 & 90.88 \\
\hline
\end{tabular}

\section{Complete references}

Ref 28: Dairaku, T.; Furuita, K.; Sato, H.; Šebera, J.; Yamanaka, D.; Otaki, H.; Kikkawa, S.;

Kondo, Y.; Katahira, R.; Bickelhaupt, F. M.; Guerra, C. F.; Ono, A.; Sychrovský, V.; Kojima, C.; 
Tanaka, Y. Direct detection of the mercury-nitrogen bond in the thymine-Hg-II-thymine base-pair with Hg-199 NMR spectroscopy. Chem. Commun. 2015, 51, 8488-8491.

Ref 49: Gaussian 09, Revision D.01, M. J. Frisch, G. W. Trucks, H. B. Schlegel, G. E. Scuseria, M. A. Robb, J. R. Cheeseman, J. A. Montgomery, Jr., T. Vreven, K. N. Kudin, J. C. Burant, J. M. Millam, S. S. Iyengar, J. Tomasi, V. Barone, B. Mennucci, M. Cossi, G. Scalmani, N. Rega, G. A. Petersson, H. Nakatsuji, M. Hada, M. Ehara, K. Toyota, R. Fukuda, J. Hasegawa, M. Ishida, T. Nakajima, Y. Honda, O. Kitao, H. Nakai, M. Klene, X. Li, J. E. Knox, H. P. Hratchian, J. B. Cross, V. Bakken, C. Adamo, J. Jaramillo, R. Gomperts, R. E. Stratmann, O. Yazyev, A. J. Austin, R. Cammi, C. Pomelli, J. W. Ochterski, P. Y. Ayala, K. Morokuma, G. A. Voth, P. Salvador, J. J. Dannenberg, V. G. Zakrzewski, S. Dapprich, A. D. Daniels, M. C. Strain, O. Farkas, D. K. Malick, A. D. Rabuck, K. Raghavachari, J. B. Foresman, J. V. Ortiz, Q. Cui, A. G. Baboul, S. Clifford, J. Cioslowski, B. B. Stefanov, G. Liu, A. Liashenko, P. Piskorz, I. Komaromi, R. L. Martin, D. J. Fox, T. Keith, M. A. Al-Laham, C. Y. Peng, A. Nanayakkara, M. Challacombe, P. M. W. Gill, B. Johnson, W. Chen, M. W. Wong, C. Gonzalez, and J. A. Pople, Gaussian, Inc., Wallingford CT, 2013.

Ref 51: D.A. Case, T. A. D., T.E. Cheatham, III, C.L. Simmerling, J. Wang, R.E. Duke, R. Luo, M. Crowley, R.C. Walker, W. Zhang, K.M. Merz, B. Wang, S. Hayik, A. Roitberg, G. Seabra, I. Kolossváry, K.F. Wong, F. Paesani, J. Vanicek, X. Wu, S.R. Brozell, T. Steinbrecher, H. Gohlke, L. Yang, C. Tan, J. Mongan, V. Hornak, G. Cui, D.H. Mathews, M.G. Seetin, C. Sagui, V. Babin, and P.A. Kollman AMBER 10, University of California, San Francisco: 2008. 